\section{DIGITAL COMMONS \\ @ UNIVERSITY OF SOUTH FLORIDA}

\section{(Q)GER}

Journal of

Global Education and Research

June 2018

\title{
The practice of administrative supervision in an international context - The case of Vietnam
}

Lou L. Sabina

Stetson University, Isabina@stetson.edu

Katherine A. Curry

Oklahoma State University, katherine.curry@okstate.edu

Follow this and additional works at: https://digitalcommons.usf.edu/jger

Part of the Education Commons

This Refereed Article is brought to you for free and open access by the M3 Center at the University of South Florida Sarasota-Manatee at Digital Commons @ University of South Florida. It has been accepted for inclusion in Journal of Global Education and Research by an authorized editor of Digital Commons @ University of South Florida. For more information, please contact digitalcommons@usf.edu.

\section{Recommended Citation}

Sabina, L. L., \& Curry, K. A. (2018). The practice of administrative supervision in an international context The case of Vietnam. Journal of Global Education and Research, 2(1), 45-59. https://www.doi.org/ $10.5038 / 2577-509 \times .2 .1 .1022$

Corresponding Author

Lou L. Sabina, Stetson University

Revisions

Submission date: Sep. 17, 2017; 1st Revision: Feb. 13, 2018; 2nd Revision: Feb. 21, 2018; Acceptance: Jun. 30, .2018 


\title{
The Practice of Administrative Supervision in an International Context - The Case of Vietnam
}

\author{
Lou L. Sabina ${ }^{1}$ and Katherine A. Curry ${ }^{2}$ \\ ${ }^{1}$ Department of Education \\ Stetson University, United States \\ lsabina@stetson.edu \\ ${ }^{2}$ School of Educational Studies \\ Oklahoma State University, United States \\ katherine.curry@okstate.edu
}

\begin{abstract}
Collaborative international partnerships offer important benefits for institutions of higher education, both domestically and abroad. Recently, a Midwestern institution formed an important partnership with a sister institution in Vietnam that provides opportunities for cultural and academic exchange across cultures that differ dramatically. Very little research has been conducted in Vietnam, especially regarding instructional supervision. Using a collaborative, developmental model of supervision, this paper analyzes the influence of introducing a relationship oriented model of supervision as professional development training to principals in Vietnam. Findings indicate both challenges and opportunities for this collaborative leadership style in the context of education in Vietnam.
\end{abstract}

Keywords: principals, leadership, teacher training, principal training, instructional leadership

\section{Overview}

Collaborative international partnerships can offer important benefits for institutions of higher education, both domestically and abroad. Recently, a Midwestern institution has formed an important partnership with a sister institution in Vietnam. This partnership provides opportunities for cultural and academic exchange across cultures that differ dramatically. Specifically, professional development training provided by the U.S. university offered an opportunity for faculty members from the U.S. institution to share supervisory practices based on a formative approach to instructional supervision in a context where summative understandings of supervision have primarily been practiced (Hallinger \& Bryant, 2013). Additionally, focusing on leadership practices in the U.S. provided an opportunity to share a formal knowledge base of school leadership, something that research has indicated is limited in the country of Vietnam (Hallinger \& Bryant, 2013). In this study, we sought to understand the influence of this instructional supervision training during a week-long intensive in-service session for principals in Vietnam. This understanding is important because the concepts that were addressed, utilizing formative instructional supervision to promote teacher growth and development, differ greatly from the practices of Vietnamese principals. The opportunity to present this information allowed a platform 
for the exchange of ideas and furthered understandings of cultures that differ dramatically.

Faculty members from the U.S. institution traveled to Vietnam to provide training regarding perspectives on American education to current vice-principals and principals in one specific province in Vietnam. University administrators from this sister institution in Vietnam had established the goal of promoting principal growth and development. This training, in response to their invitation to guide professional development training for these professionals, served several purposes. It provided an opportunity to establish collegial relationships between educational professionals at this institution and administrators in the Province, and it provided an opportunity to gain a better understanding of the expectations of principals in Vietnam and to learn how principals are trained to meet those expectations.

Very little research has focused on instructional supervision in Vietnam, and this paper offers insight into the effectiveness of instructional supervision training in a country where principals have very little authority or autonomy to make decisions. This training utilized the formative Clinical Supervision model advanced by Glickman, Gordon, and Ross-Gordon (2014). This qualitative study analyzed survey data from four open-ended response questions from in-service participants concerning their perceptions of the developmental supervision model, role-plays conducted during the training, and whether or not the scenarios would be effective in the context of Vietnamese education.

\section{About the Study}

In April 2015, two faculty members from a large, Midwestern research university traveled to a university in Vietnam to participate in a week-long professional development program for principals and vice-principals. This experience was unique for the university in Vietnam due to the fact that this in-service was the first time that faculty from North America had been invited to lead a professional development session for principals. Sessions were held for five days for seven hours each day. Sessions focused on topics in Teaching Management (Instructional Supervision), Organizational Theory, Data-Driven Decision Making, Collaborative Leadership, School Administration Training in the US, and Student Assessment. In this study, we focus primarily of the influence of the training on instructional supervision on principal perceptions and practices. One faculty member was responsible for all preschool and kindergarten administrators $(n=46)$, and the other faculty member was responsible for all elementary, middle, and secondary administrators $(n=61)$. One session, Teaching Management, was a joint session in which both faculty members taught formative assessment using the Glickman, Gordon, and Ross-Gordon model of Clinical Supervision. Additionally, supervisory leadership behaviors were demonstrated for the students using the technique of role play.

\section{Purpose of Study}

The purpose of this qualitative case study was to understand principal responses to the introduction of a Westernized, relationship oriented, supervisory model that, likely, differed from their current practices. We were interested in understanding Vietnamese principal perceptions of their own supervisory practices and how the introduction of a supervisory model that differed from their own influenced their perception of leadership. It is important to recognize that conceptualizations of instructional leadership have, historically, ignored the influence of the socio-cultural context 
(Bajunid, 1996; Hallinger \& Leithwood, 1996). This study offered the opportunity to introduce a new understanding of instructional supervision in a context dramatically different from the context in which this model was developed. Additionally, this study is important because published research on leadership practices in Vietnam tend to "reaffirm the wisdom of existing political decrees and policies" (Hallinger, Walker, Nguyen, Truong, \& Nguyen, 2017, p. 224). Therefore, this study offered the opportunity to understand principal responses to a relationally based instructional leadership paradigm in a culture that is strongly influenced by cultural norms of power distance (hierarchy) and collectivism (Hallinger, et al., 2017).

Developmental supervision, as a model for instructional leadership, has been widely accepted in the United States (Glickman et al., 2014) as an approach to teacher development. Developmental Supervision adapts to individual teacher needs and provides opportunity for teacher growth based on the developmental needs of individual teachers. Demonstrating a supervisory model that employs formative, versus summative, evaluation offered an important opportunity to introduce understandings of a formative approach to instructional supervision to these principals concerning supervisory practices. This supervisory approach supported objectives described by University administrators in Vietnam and, therefore, offered an important opportunity to evaluate the responsiveness of administrators to a more collegial and collaborative form of supervision in a system that, historically, included primarily hierarchical authority structures utilizing exclusively summative evaluation practices (Hallinger et al., 2017). Additionally, it provided an opportunity to introduce a relational approach to leadership that emphasizes the principal's role as instructional leader (Glickman et al., 2014). This approach challenges the traditional approach of priority given to political and managerial roles that is commonly practiced in Vietnam (Hallinger et al., 2017).

Four research questions guide this study:

(1) What are principals' perceptions about the type of supervisory behavior that is most commonly practiced in Vietnam?

(2) How do principals perceive the need for formative (versus summative) teacher assessment?

(3) How do these principals respond to a collaborative model of supervision?

(4) What are principals' perceptions about barriers that exist for implementation of a collaborative model?

\section{Literature Review}

Instructional supervision and formative and summative evaluation of teachers continues to be a critical role and responsibility of school administrators (Kachur, Stout, \& Edwards, 2013; Lortie, 2009; Marzano, 2011). Understanding appropriate forms of interaction to inspire and motivate teachers can play an important role in the mentoring and development of teachers (Pajak \& Glickman, 1989; Siens \& Ebmier, 1996; Snow-Gerono, 2008). In Vietnam, "significant progress is being made in terms of improving educational quality" (Thao \& Boyd, 2014, p. 184). Significant reform efforts to improve the implementation of the national curriculum and the quality of education began in 2003 (de Los Angeles-Bautista, 2001) at the urging of the National Ministry of Education. Despite these reform efforts, barriers still exist between administration and teachers, causing disconnect in practices such as leadership for instructional improvement. 
Efforts to understand educational leadership training and scholarship in the country of Vietnam are limited (Hallinger et al., 2017). Hallinger, Walker, \& Gian (2015) found, through a review of Vietnamese research, that limitations exist in studies comprising the Vietnamese knowledge base in school leadership. Among these limitations is a lack of a critical perspective on the phenomena being studied, and weak methods with respect to the reliability and validity of the results (Hallinger et al., 2015). Additionally, even though efforts have been made to decentralize decision making in schools and empower teachers to take responsibility for decisions that are made, formal power remains with the school principal, and teachers are generally reluctant to assume responsibility in decision making (Hallinger et al., 2017). Additionally, principal involvement as instructional leader has been "confused, lacking coordination, casual and arbitrary, unsystematic, and formalistic" (Hallinger \& Troung, 2014, p. 54). With school effectiveness measured through annually submitted goals, referred to as school targets, to the Ministry of Education and Training (Hallinger et al., 2017), pressure remains on principals to enhance educational outcomes. However, the literature suggests that instructional leadership receives little attention from principals (Hallinger, 2011; Hallinger \& Trong, 2014; Hallinger et al., 2015; Lee \& Hallinger, 2012; Walker $\&$ Hallinger, 2015) and that supervisory practices are primarily summative.

\section{School Leadership in Vietnam}

A review of the literature helps to explain the existing context in which school leadership is constructed in Vietnam. Principals in Vietnam are considered government officers and serve as political representatives of the Communist party (Hallinger et al., 2017). Therefore, although reforms were put in place as directives of the Communist part in 2004 to enhance administrator quality (Pham, 2013), principals often assign greater priority to their political and managerial roles than they do to the role of instructional leader (Hallinger \& Truong, 2014). Principals in Vietnam are responsible for meeting school targets that are primarily set through a process of matching the "targets and strategies in both the education bureaucracy as well as the Communist party" (Hallinger et al., 2017, p. 228). These targets are set through a process in which the principal selects from a set of officially sanctioned targets as defined by the Ministry of Education and Training (MOET). Evaluation of the performance of schools in Vietnam, and the success of the principal in leading those schools, hinges primarily on achieving these targets as established in their newly established system of evaluation. This system focuses on assigning government or city level medals based on three criteria: a) the percentage of students graduating successfully, b) the number of students receiving awards in academic competitions, and c) the number of merit titles achieved by teachers (Hao \& Wu, 2012). However, the requirements to earn the title of Merit Teacher are very high, and most awards do not go to teachers, but instead, to managerial staff.

In addition to these criteria, Hallinger et al., (2017) found that principals felt responsible for building solidarity in their buildings and managing external relationships. Hofstede (1980) suggests that the emphasis on building solidarity is closely linked with the Confucian norm of collectivism, and the expectation of managing external relationships is closely tied to the sociocultural value of power distance. According to Hallinger et al., (2017), these expectations reflect "the realities of resource dependence in an education context with high expectations but relatively low levels of funding" (p. 235). Another factor that influences principal leadership in Vietnam is the expectation that principals must be a member of the Communist party, and principals must maintain strong relationships with political and educational officers. Officials in the Ministry of Education and Training and the Communist party share in the authority to set educational policy, 
implement curriculum, select and train teachers, and allocate financial resources (Hallinger et al., 2015; Hallinger et al., 2017; Hallinger \& Truong, 2014). Therefore, strong relationships with officials in the Communist party are essential for maintaining credibility and legitimacy for building leaders (Hallinger et al., 2017). Further, in Vietnam, the principal is the face of the school, and principals are held responsible for implementing initiatives for improving teachers' professionalism and the educational quality in schools (Pham, 2013).

In 2004, the Communist Party of Vietnam passed Directive No. 40/TW, implementing a standardsbased evaluation system for teachers (Pham, 2013). This initiative mandated that teachers take responsibility for developing their professionalism in teaching, ethics, and knowledge of culture (VNMOET, 2007). Principals are responsible for instructional curriculum implementation, assigning school duties of teaching staff and employees, and evaluating the performance of their subordinates (Pham, 2013). Even though principals often delegate supervisory responsibilities to vice-principals or department heads, they retain responsibility for teacher performance in their schools. Additionally, although the standards-based evaluation system was introduced and implemented in 2010-2011 (Pham, 2013), teachers must still receive an annual evaluation from the Vietnam Ministry of Home Affairs. In secondary schools, teachers must also complete a selfevaluation (with summative scores), receive a summative evaluation by the department of the teacher, and receive an evaluation by the principal. The principal's evaluation is shared with departments and teachers, and all reports go to higher levels of administration (Pham, 2013). In sum, teacher evaluation in Vietnam is driven by standards-based evaluation, teacher selfevaluation, and summative evaluation by the teacher's department and principal. These steps in the evaluation process are intended to promote development of teacher quality and enhancement of professional skills (Pham, 2013).

\section{Theoretical Framework}

The theoretical framework utilized for this paper is transactional/transformational leadership in schools (Bass, 1985). Although these theories have been explored extensively in educational leadership literature, they are extremely effective in assessing the differences between supervision in Vietnam and the United States. Supervision in Vietnam reflects corrective transactions and active and passive interactions (Bass, 1985; Northouse, 2016), a technique that Vietnamese educational leaders described as a commonly used practice (student interview). However, a transformational approach is more common in the United States with more intellectual stimulation and individualized consideration to develop teachers to their fullest potential (Avolio, 1999). Research in effective supervision techniques suggests that, when conducting teacher observations or evaluative conversations with teachers, an effort should be made to empower teachers and create capacity for their development (Glickman et al., 2014). However, when barriers exist that prohibit appropriate developmental conversation (Gordon, 1997), the art of supervision may be lost.

\section{Glickman, Gordon, Ross-Gordon Model of Clinical Supervision}

The Glickman, Gordon, Ross-Gordon model of supervisory behaviors began to develop in the late 1980s through the mid-1990's, and has been one of the most frequently cited models of clinical supervision in educational literature. The model, a four-tiered approach to conferencing with teachers, focuses on four distinct supervisory approaches. These approaches are not mutually exclusive categories. Instead, according to Glickman et al. (2014), supervisory behavior exists on 
a continuum, and successful supervisors move along that continuum to choose supervisory behavior to meet the developmental needs of an individual teacher. Historically, the model emerged from work of Glickman and Pajak (1986) and Pajak and Glickman (1989), which looked at the use of informational language of supervisory conferences and the perceptions of teachers from those conferences. Further exploratory work on this model continued from Gordon (1990), who began to dissect the informational language further in terms developing a continuum for the model and ways in which developmental supervision could aid both supervisors and administrators. The model eventually emerged into the most current iteration (Glickman et al., 2014): a four-tiered approach focused on specific supervisory behavior. These behaviors are defined as:

- directive control, in which the supervisor assigns the plan of approach to the teacher, and determines the specific steps for the teacher to follow

- directive informational, in which the supervisor suggests the plan of approach to the teacher, and restricts their choice on possible solutions

- collaborative interpersonal, in which the supervisor attempts to understand the teacher's point of view but still presents his or her own ideas and arriving on a mutually-agreed upon solution

- nondirective interpersonal, in which the supervisor listens to the teacher's perceptions and then ultimately leaves the decision in the hands of the teacher. (Glickman et al., 2014, pp. 191-192)

It is worth noting that, Glickman et al. (2014) emphasize the importance of tailoring supervisory approaches to meet developmental needs of individual teachers. For example, a highly motivated, experienced teacher may benefit from nondirective interpersonal supervision as a means to enhance innovation and creativity in the classroom. In contrast, an inexperienced or unmotivated teacher may benefit from a more directive approach to supervision, as these approaches provide important administrator support for continued and targeted professional growth.

After examining other models of clinical supervision, the two faculty members chose this model due to their familiarity in both professional practice and teaching with the model; its high regard in the educational community (Blase \& Blase, 2000; Clifford, Macy, Albi, Bricker, \& Rahn, 2005; Swafford, 1998); and also because of the authors' approach of the model of conversation as a formative, and not summative, approach to supervision. Sullivan and Glanz (2013) state, "Many supervisors over the years have used this approach, many continue to follow it, and you may favor it yourself" (p. 42). We found this model to be the most effective and simple method to translate to a group of over 100 Vietnamese faculty, and we used role play situations to demonstrate each of the four dimensions of the model.

\section{Methods}

We chose qualitative research as qualitative research "takes an interpretive, naturalistic approach to its subject matter" and "qualitative researchers study things in their natural settings, attempting to make sense of, or interpret phenomena in terms of the meanings that people bring to them" (Jones, 1995, p. 2). As the researchers were in Vietnam working with school administrators who spoke English as a Second Language or did not speak English, qualitative research allowed for clarification and approach to meaning that could be addressed, whereas quantitative research may 
have not. After providing comprehensive instruction concerning the concept of Clinical Supervision (Glickman et al., 2014), faculty members presented four role-plays of administrative conversations with teachers based on the supervision model proposed by Glickman et al. (2014). Role plays included an example of directive control behaviors, directive informational behaviors, collaborative behaviors, and nondirective behaviors. During the in-service, participants watched faculty interactions demonstrating each type of leadership behavior. All discussions were translated into Vietnamese through a translator. Students asked questions following each scenario, and they engaged in collaborative discussions concerning each type of leadership behavior. Instruction and scenarios were presented to participants over a two-day time period, providing them with thorough exposure to each of the four models of supervision. At the conclusion of roleplays and instruction, participants engaged in classroom discussions (facilitated by a Vietnamese translator), and they responded to a short open-ended survey. Questions in the survey were developed based on the main concepts from the Glickman et al. model.

\section{Data Analysis}

The sample size of respondents was $n=107$, of which 46 were preschool and kindergarten principals, and 61 were elementary, middle, and high school principals. Survey responses were stratified first by preschool and kindergarten responses vs. elementary, middle, and high school responses, and then categorized together to assess commonalities. Text was dissected into segments using the coding framework (Miles, Huberman, \& Saldana, 2013), which allowed for more in-depth analysis and investigation of themes across all respondents. Triangulation of data occurred through the careful inspection of researcher notes, reflections, and observations of interactions between principals during class discussions, meals, and scheduled break times.

Two Vietnamese faculty members proficient in English translated the questionnaire into Vietnamese, and the same faculty members re-translated participant responses back into English, to ensure continuity. Additionally, to ensure validity, we asked two other Vietnamese speaking individuals to translate the Vietnamese questionnaires back into English. Despite the precautions taken to ensure appropriate translation, it appeared, during translation, that some of the participants did not understand specific questions on the survey. As a result, we removed those responses from our data analysis, resulting in a total sample size of $n=86$ for research question number one. We included all participant responses $(n=107)$ in data analysis for research questions two, three and four. Our coding structure used a number dimension as follows:

- $1=$ preschool or kindergarten principals

- $2=$ secondary principals

followed by

- 01 through 46 - preschool or kindergarten principals

- 01 through 61 - secondary principals

For example, (1-46) would be a preschool or kindergarten principal, and the $46^{\text {th }}$ respondent to our survey. 


\section{Findings}

Research Question \#1: What are principal perceptions about the type of supervisory behavior most commonly practiced by these principals in Vietnam?

Our first research question directly addressed the supervisory behavior that administrators felt was the most practiced in their school context. Administrators were asked which of the four supervisory behaviors was the one that was practiced the most frequently in their school system. Table 1 reflects administrator responses.

Table 1. Perceptions of Supervisory Behavior

\begin{tabular}{lrrrrrr}
\hline Behavioral Model & $\begin{array}{c}\text { Preschool and } \\
\text { Kindergarten } \\
\text { Principals } \boldsymbol{n = 4 0}\end{array}$ & $\begin{array}{c}\text { Elementary, Middle, } \\
\text { and Secondary } \\
\text { Principals } \boldsymbol{n = 4 6}\end{array}$ & \multicolumn{2}{c}{$\begin{array}{c}\text { Total of All } \\
\text { Administrators } \\
\boldsymbol{n}=\mathbf{8 6}\end{array}$} \\
\hline & $\boldsymbol{n}$ & $\mathbf{\%}$ & $\boldsymbol{n}$ & $\mathbf{\%}$ & $\boldsymbol{n}$ & $\mathbf{\%}$ \\
\hline Directive Control & $24 / 40$ & 60 & $30 / 46$ & 65 & $54 / 86$ & 62 \\
\hline Directive Informational & $7 / 40$ & 16 & $8 / 46$ & 17 & $15 / 86$ & 17 \\
\hline Collaborative Interpersonal & $9 / 40$ & 24 & $4 / 46$ & 9 & $14 / 86$ & 16 \\
\hline Nondirective Interpersonal & $0 / 40$ & 0 & $4 / 46$ & 9 & $4 / 86$ & 5 \\
\hline
\end{tabular}

$\mathrm{N}=86$ for Research Question 1

Of the $n=46$ responses from the preschool and kindergarten principals, $n=40$ were valid and reflected practices discussed as part of the four-tier Glickman model or the role play. Overwhelmingly, the directive control model was the model that principals stated was practiced the most (60\%). A principal (1-32) commented on his experiences as a clinical supervisor. He stated, "In a school, besides the teachers who are hardworking and work well, there are some who don't have sense of cooperation to the manager. The manager must always have measures for controlling and punishing to help these negative teachers." The idea that controlling and punishing was a help to teachers reflected supervisory practices synonymous with the directive control model. A frequent discussion that took place during the week-long training was the notion that principals felt completely powerless in their ability to hire or fire teachers, noting that government officials had complete autonomy over the human resources function of teachers. This sentiment was reflected by one respondent (1-03) in her response, nothing that "in Vietnam, they have to do or obey the law in regulations. For example, the school master, the school head has no right to make final decisions to fire a teacher." This lack of influence in hiring/firing decisions may be the reason why this particular population of principals leaned so much toward the directive control method, as it provided them with the control and autonomy to influence teacher performance, a factor over which they are held strictly accountable.

Of the $n=61$ responses from the secondary principals, $n=46$ were valid and reflected practices discussed as part of the four-tier Glickman model or the role play. A similar response was echoed by the elementary, middle, and high school principals, with 30 out of $46(65 \%)$ of respondents noting that the direct control model was the one they were most accustomed with in their professional experience. Additionally, approximately 1 out of every $6(17 \%)$ principals discussed their experiences with the directive informational model. A respondent (2-61) noted that it was beneficial to provide the teacher with alternatives and allow him/her to make a choice regarding alternative solutions. This person stated, 
The headmaster says 'no' and suggests 3 alternatives: Talking to parents on the phone, meet face to face with parents, asking his staff to facilitate. After all, the teacher agrees with those three alternatives. I really like this solution to the problem, and I think I will use it in my job.

Even though the respondent spoke about not using a control model, the wording ("the headmasters says "no"') may suggest an overarching preference for the directive control model. It is worth mentioning that four respondents in this group specifically noted the nondirective interpersonal method as the model they desired to use.

Research Question \#2: How do principals perceive the need for formative (versus summative) teacher assessment?

Responses about different models of clinical supervision also led to discussions regarding formative and summative assessment. Although survey questions did not specifically address respondent experiences with formative assessment, classroom discussion identified the fact that formative assessment is not a typical practice among these administrators. Their responses indicated an interest in formative assessment and learning more about the process to use in their schools. One respondent (2-47) noted the importance of gaining a deeper understanding of supervision. She mentioned a need to know, "what the principal needs to prepare in pre, while [during the observation], and post-supervision [observation]. As a result, we can supervise more effectively and build better relations between the dean and teachers, teachers and teachers, and teachers and students." A positive aspect of this response was that this same respondent noted that her primary experience in Vietnam was with the direct control model, but she seemed amenable to learning about different types of supervision and different types of methods to build relationships with her staff. One respondent (2-21) recognized the differences between formative and summative assessment, noting her biggest "takeaway message" from the week was that "observation is different from evaluation." It is worth noting that this response reflects accomplishment of one of the goals of the in-service experience: for students to develop an understanding about the differences between observing/supervising teachers and evaluating teachers. Another principal (2-56) commented that, "The clinical supervision is different from what I have been doing. That is asking the teachers to sum up what they have already done. We earnestly hope that clinical supervision will yield more productive outcomes in the governmental office."

Two other respondents reflected similar experiences with summative assessment rather than formative assessment. One principal stated that, "It's different here [Vietnam] that the headmasters don't summarize the measures after negotiating" (2-03), and another indicated that "supervision is different than what I am doing, every method is required to summarize the tentative action and next actions" (2-04). These responses may indicate that these principals do not have exposure to formative evaluation, and with increased exposure, they may be able to build formative assessment into their model of supervision in their schools.

Research Question \#3: How do these principals respond to a collaborative model of supervision?

Two questions on the survey addressed cooperation and collaboration. One question was explicit, and was answered by all 107 survey respondents. Respondents were asked, "What is your 
understanding of the meaning of 'cooperation'?" Responses to this question directly addressed supervision. Secondly, those respondents who commented on the importance of a collaborative model included their perceptions of potential benefits of collaborative leadership.

Concerning the importance of collaboration, one respondent (1-02) spoke about collaboration as an important part of supervision and teacher conferencing. He noted, "Listen to the point of view of the teachers and give your point of view as the leader. Solving the problems based on the context and come up with common interest." This response indicates a willingness of the principal to hear the perspectives of his teachers and to find common interests or parallels in their approaches. Another principal (1-18) also spoke about how useful the cooperative model was, commenting that "Cooperative situation is the most useful because the management listens to the teachers and based on the teachers' perceptions, the management will understand more and give more effective direction." The willingness to "seek first to understand" indicates concern for the teaching staff and a willingness to work together with teachers.

Responses were also noteworthy when principals were asked to define what cooperation meant to them. One respondent (2-20) addressed how cooperation leads to school improvement, stating that, "Administrators, leaders, and teaching staff plan together to bring up targets that will develop schools. All of them discuss and bring out or suggest solutions, and plans to reach targets." Another respondent (1-28) echoed a similar response, defining cooperation as, "Expressing personal viewpoints and discussing some solutions to consider the effectiveness and result of solutions. They can reach an agreement and suggest some specific solutions to achieve the final objective." All respondents seemed to understand what cooperation and collaboration meant; however, some indicated barriers to implementing those types of models in their professional practice.

Research Question \#4: What are principal perceptions about challenges that exist for a collaborative model?

The final question concerned the perception of barriers that existed for employing a collaborative model of supervision. Although respondents were quick to address the challenges of collaboration, some were optimistic that elements of the model could be taken and integrated into their schools and practices. Of the $n=46$ preschool and kindergarten principals, 16 (35\%) expressed a barrier that existed with clinical supervision. Of the $n=61$ elementary, middle, and high school principals, 19 (31\%) discussed a barrier to clinical supervision. Table 2 lists all barriers that respondents indicated at least once in their survey responses.

The first barrier appears to be one that could be easily remedied within the context of individual schools: not having time to meet after a conference with teachers to follow-up on the decisions that were discussed as part of the meeting. Ten respondents indicated that the model used in Vietnam did not allow time for follow-up discussion, and, instead, the role of the principal was more for documentation purposes than actual supervision. One respondent (2-15) noted, "when we do observations in Vietnam, the observer records everything, the process, the procedures, the methods, and then the observer gives grades to the teacher and then they classify it. Here in Vietnam, the skills are classified into four types: Distinction, Credit, Average, and Unsatisfactory." We felt this was interesting, as the teachers are assigned one of four classifications; however, there was no mention of a pre-or-post conference. While we classify this 
finding as a potential barrier, it is well recognized that one of the challenges to Clinical Supervision, documented by Glickman et al. (2014) is that this model of supervision does require dedicated time for its effectiveness.

Table 2. Challenges to Collaborative Model of Supervision

\begin{tabular}{lrrrrrr}
\hline Barriers Addressed in the Study & $\begin{array}{c}\text { Preschool and } \\
\text { Kindergarten } \\
\text { Principals } \\
\boldsymbol{n}=\mathbf{1 6}\end{array}$ & $\begin{array}{c}\text { Elementary, Middle, } \\
\text { and Secondary } \\
\text { Principals } \\
\boldsymbol{n}=\mathbf{1 9}\end{array}$ & $\begin{array}{c}\text { Total of All } \\
\text { Administrators } \\
\text { Responding with a Barrier } \\
\boldsymbol{n}=\mathbf{3 5}\end{array}$ & \begin{tabular}{c} 
\% \\
\hline
\end{tabular} \\
\hline $\begin{array}{l}\text { No time to meet after the } \\
\text { conference - not part of the } \\
\text { supervision process }\end{array}$ & $3 / 16$ & 19 & $7 / 19$ & 65 & $10 / 35$ & 29 \\
\hline Lack of power to terminate teachers & $8 / 16$ & 50 & $2 / 19$ & 11 & $10 / 35$ & 29 \\
\hline $\begin{array}{l}\text { Government control over the school } \\
\text { process as a whole }\end{array}$ & $3 / 16$ & 19 & $4 / 19$ & 21 & $7 / 35$ & 20 \\
\hline $\begin{array}{l}\text { Teachers may lack the willingness } \\
\text { to grow professionally due to low } \\
\text { salary }\end{array}$ & $2 / 16$ & 13 & $3 / 19$ & 16 & $5 / 35$ & 14 \\
\hline $\begin{array}{l}\text { Unclear supervision responsibilities } \\
\text { of principals }\end{array}$ & $1 / 16$ & 6 & $2 / 19$ & 11 & $3 / 35$ & 9 \\
\hline $\begin{array}{l}\text { Cultural barriers in providing } \\
\text { teachers with compliments }\end{array}$ & $0 / 16$ & 0 & $1 / 19$ & 5 & $1 / 35$ & 3 \\
\hline
\end{tabular}

The next barrier was much more explicitly addressed, with ten respondents specifically noting they were powerless to terminate teachers in their buildings even when teacher behavior was egregious. In Vietnam, the terminology used by respondents is to sack a teacher, instead of termination or firing. It should be noted though that the majority of respondents who expressed this limitation as a barrier were the preschool and kindergarten principals, many of whom are new to their positions as principals, as Vietnam has only recently begun to expand access to preschool and kindergarten for children. Six responses reflecting this barrier follow in Table 3:

Table 3. Responses Concerning Lack of Power to Terminate Teachers

\begin{tabular}{ll}
\hline Participant & \multicolumn{1}{c}{ Comment } \\
\hline $\mathbf{1 - 1 9}$ & $\begin{array}{l}\text { "In Vietnam, the school head has no right to sack any teachers. That is the right and } \\
\text { responsibility of the district's government." }\end{array}$ \\
\hline $\mathbf{1 - 2 4}$ & "In Vietnam, the headmaster doesn't have authority to recruit the teachers, or sack the teachers." \\
\hline $\mathbf{1 - 2 5}$ & "In our school, there are a few cases where a teacher turns up late or violates school regulation; \\
& "Se/she does not get a sack." \\
& "Some measures stated here is not suitable in Vietnam. My school still ignores the situations in \\
& mistakes will not get a sack." \\
\hline $\mathbf{2 - 3 5}$ & "The headmaster should be severe to his staff and he should be given the authority to sack \\
& regulation violators. But in my school, reprimanding is what my headmaster does, and I regret \\
& that." \\
\hline $\mathbf{2 - 5 2}$ & $\begin{array}{l}\text { "We have no right to fire teachers. We punish them instead. If a teacher doesn't cooperate or } \\
\text { raise their voice. We give them directions and prompts. They listen to what I say." }\end{array}$ \\
&
\end{tabular}

Principals expressed concern that, even though they are considered to be the head of the building, they lacked the autonomy to recruit or discipline teachers. These responses indicated a potential disconnect between principal autonomy to make personnel decisions and the responsibility that 
they felt for organizational outcomes. We found that principals were responsible for outcomes; however, they may have limited authority to actually influence teacher behavior in ways that could lead to enhanced student outcomes.

Concerns regarding teacher salary were addressed by three of the respondents. One principal, (206) noted that "the salary is very low, which causes difficulties for the teachers in general. The result of that is many teachers teach the wrong subjects, and they cannot invest intensively on the professional skills." While the impetus of a lower wage for teachers may not be specific to Vietnam, lower salaries may lead to less motivation for teachers. According to Glickman et al. (2014), less motivation may, in turn, lower the opportunity for improvement of the use of collaborative methods as development approaches are largely determined by teacher commitment to self-improvement.

Another barrier to collaborative supervision was the perception of the principals that their primary responsibility was student supervision rather than teacher supervision. One respondent (2-18), specifically addressed a desire to be more involved with teacher supervision, stating that,

I will perform as a supervisor but I do not want to supervise the students. This is not my job. I only want to supervise the teachers. ... And the results are not good enough. This is because I spend too much time with students.

Another respondent (1-06) noted a similar desire stating "Meanwhile, in America, the headmaster takes charge and supervises teachers; in Vietnam, the headmaster takes charge of students." These statements indicate that these principals in Vietnam considered their primary responsibility to be student supervision with less emphasis on teacher supervision. This barrier appears more organizational, but could be aligned with the lack of autonomy that principals/headmasters have over their teaching staff.

Finally, one administrator (2-08) noted that there were cultural challenges preventing more collaborative supervisory models, noting that, "Vietnamese people are not in the habit of complementing other people to encourage. They are afraid that compliments will lead to conceitedness." To this principal, the perception of collaboration was associated with providing compliments, an element that was not mentioned in class discussions.

\section{Discussion}

Our findings indicate both challenges and opportunities for collaborative leadership in Vietnam. The openness of university administrators to invite instructors from the United States to introduce Clinical Supervision, a clearly developmental approach to supervision, suggests that approaches to principal leadership are changing in the country. While organizational structures in Vietnam have, historically, supported transactional leadership styles, evidence from this study suggests that university leaders and principals are interested in collaborative approaches to leadership. The model of transformational leadership, where collaboration between leaders and followers "raises the level of motivation" in the follower (Northouse, 2010, p. 172) may become a reality as principals begin to understand particular developmental needs of their teachers. Principals in this study seemed eager to embrace leadership styles that "help followers to reach their fullest potential" (Northouse, 2010, p. 172). In fact, when transformational leadership was introduced 
during the in-service activities, these principals expressed a strong preference for transformational leadership over transactional style of leadership. What is interesting to note is the recognition, among these principals, that current organizational structures may not promote transformational type behaviors, specifically when principals feel responsible for school outcomes without the authority to make important personnel decisions. However, findings from this study suggest that these principals are interested in collaborative approaches to meet some of the supervisory challenges that they face.

Another significant finding from this study was the interest of these principals in formative supervision as a means to supplement their summative responsibilities. This study revealed that, prior to this training, administrators in Vietnam were unfamiliar with formative assessment for teachers. Vietnamese participants reflected a summative nature to their supervision experiences, an approach reflected in a very transactional type of leadership. As is sometimes observed in the United States, the terms "supervision" and "evaluation" were used interchangeably. Introducing supervision as a means to promote teacher growth, formative supervision, piqued the interests of these principals. Given their current contextual situations, formative supervision may help promote the type of relationships that lead to cooperative efforts for school improvement.

Additionally, although principals participated in this in-service as a group, the structure of their working environments precludes them from collaborating with each other in their normal working environments. As a result, enthusiasm expressed about collaborative approaches to leadership may actually diminish over time due to a lack of collaborative opportunities among principals. However, the opportunity to bring these principals together, as a group, provided a platform for collaboration among these influential individuals. This type of in-service training offers important promise for collaborative efforts in a quickly developing province.

It is also worth noting that cultural differences between the United States and Vietnam may indicate that current models of collaborative leadership that are implemented successfully in the United States may not provide a successful model to meet educational objectives in Vietnam. Models should be adjusted to appropriately address cultural expectations and norms in a country. For example, the understanding, by one principal in the study, that collaboration was synonymous with complimenting his teachers indicates that training and implementation concerning supervisory practices should keep cultural differences at the forefront of planning and discussions. It cannot be assumed that a supervisory model can be applied in a blanket style approach without first considering the culture of the individuals involved, how individuals might interpret ideas presented, objectives of supervisory practices in a country, and supervisory practices that could benefit students within these systems. Additionally, our experience underscores the importance of ongoing dialogue between trainers and trainees so that misunderstandings can be addressed and identified as they arise. In sum, training for supervision should be very mindful of specific needs of organizations within their own cultural contexts.

\section{Future Implications}

Implications for research and practice include the need to continue to understand the opportunity for implementation of collaborative leadership for enhanced school outcomes in Vietnam. Different cultures have different practices, and understanding the cultural context of Vietnamese and Asian education will help provide support as needed within the appropriate cultural context. 
These experiences have presented opportunities to further develop principal understandings of collaboration and formative assessment in Vietnamese schools and the opportunity to evaluate the effectiveness of this model in current organizational structures. Although it its infancy, the findings presented in this paper offer insight to the beginning of a transcultural strategic partnership between a United States Educational Leadership preparation program and Vietnamese professional development that will, ultimately, lead to more collaborative processes within schools.

\section{References}

Avolio, B. (1999). Full leadership development: Building the vital forces in organizations. Thousand Oaks, CA: SAGE.

Bajunid, I. A. (1996). Preliminary explorations of indigenours perspectives of educational management: The evolving Malaysian experience. Journal of Educational Administration, 34(5), 50-73.

Bass, B. (1985). Leadership and performance beyond expectations. New York, NY: Free Press.

Blase, J., \& Blase, J. (2000). Effective instructional leadership: Teachers' perspectives on how principals promote teaching and learning in schools. Journal of Educational Administration, 38(2), 130-141.

Clifford, J. R., Macy, M. G., Albi, L. D., Bricker, D. D., \& Rahn, N. L. (2005). A model of clinical supervision for preservice professionals in early intervention and early childhood special education. Topics in Early Childhood Special Education, 25(3), 167-176.

de los Angeles-Bautista, F. (2001). Early childhood care and development at the heart of community development. Early Childhood Matters, 99(10), 22-31.

Glickman, C. D., \& Pajak, E. F. (1986). Supervisors' discrimination among three types of supervisory scripts. Educational \& Psychological Research, 6(4), 279-289.

Glickman, C., \& Tamashiro, R. (1980). Determining one's beliefs regarding teacher supervision. Bulletin, 64(440), 74-81.

Gordon, S. (1992). Paradigms, transitions, and the new supervision. Journal of Curriculum and Supervision, 8(1), 62-76.

Gordon, S. (1997). Has the field of supervision evolved to a point that it should be called something else? Yes. In J. Glanz \& R. F. Neville (Eds.), Educational supervision: Perspectives, issues, and controversies (pp. 114 123). Norwood, MA: Christopher Gordon.

Gordon, S. P. (1990). Developmental supervision: An exploratory study of a promising model. Journal of Curriculum and Supervision, 5(4), 293-307.

Hallinger, P., (2011). Leadership for learning: lessons from 40 years of empirical research. Journal of Educational Administration, 49(2), 125-142.

Hallinger, P., \& Bryant, D.A. (2013). Accelerating knowledge production on educational leadership and management in East Asia: A strategic analysis. School Leadership and Management, 33(3), $202-223$.

Hallinger, P., \& Leithwood, K. (1996). Culture and leadership in educational administration. Journal of Educational Administration, 34(5), 98-116.

Hallinger, P., \& Truong, T. D. (2014). Exploring the contours of context and effective school leadership in Vietnam. Leading and Managing, 20(2), 43-58.

Hallinger, P., Walker, A., \& Gian, T. T. (2015). Making sense of images of fact and fiction: A critical review of research on educational leadership and management in Vietnam. Journal of Educational Administration, 5(3), 445-466.

Hallinger, P., Walker, A., Nguyen, D. T. H., Truong, T., \& Nguyen, T. T. (2017). Perspectives on principal instructional leadership in Vietnam: A preliminary model. Journal of Educational Administration, 55(2), 222-239.

Hao, T. N., \& Wu, B. (2012). Much ado about many things: Principle function analysis and evaluation of principals' instructional leadership in Vietnam. International Journal of Innovative Management, Information, and Production, 3(2), 61-73.

Hofstede, G. H. (1980). Culture's consequences: International differences in work-related values. Beverly Hills, CA: Sage.

Johnson, H. (2001). Administrators and mentors: Keys in the success of beginning teachers. Journal of Instructional Psychology, 28(1), 44-49. 
Jones, R. (1995). Why do qualitative research? It should begin to close the gap between the sciences of discovery and implementation. British Medical Journal, 311, 1-2.

Kachur, D., Stout, J., \& Edwards, C. (2013). Engaging teachers in classroom walkthroughs. Alexandria, VA: ASCD.

Lam Dong Bureau of Early Childhood Education and Care (ECEC). (2010). A 10 Year Review of Educational Reform. Lam Dong: Bureau of Early Childhood Education and Care.

Lee, M. S., \& Hallinger, P. (2012). National contexts influencing principals time use and allocation: Economic development, societal culture, and educational system. School Effectiveness and School Improvement, 23(4), 461-482.

Lortie, D. C. (2009). School principal: Managing in public. Chicago, Il: University of Chicago Press.

Marzano, R., Frontier, T., \& Livingston, D. (2011). Effective supervision: Supporting the art and science of teaching. Alexandria, VA: ASCD. is E-pi

Miles, M., Huberman, M., \& Saldana, J. (2013). Qualitative data analysis: A sourcebook (3 ${ }^{\text {rd }}$ ed). London, England: SAGE.

Northouse, P. (2016). Leadership: Theory and practice. Thousand Oaks, CA: SAGE Publications.

Pajak, E., \& Glickman, C. (1989). Informational and controlling language in simulated supervisory conferences. American Educational Research Journal, 26(1), 93-106.

Pham, H. Q. (2013). The implementation of standards-based teacher evaluation in Vietnamese secondary schools: A case study in Dong Thap. Retrieved, from https://search-proquestcom.argo.library.okstate.edu/docview/1430302474/fulltextPDF/43BC84B40E764E21PQ/1?accountid=411 7

Siens, C., \& Ebmeir, H. (1996). Developmental supervision and the reflective thinking of teachers. Journal of Curriculum and Supervision, 11(4), 299-319.

Snow-Gerono, J. (2008). Locating supervision - A reflective framework for negotiating tensions within conceptual and procedural foci for teacher development. Teaching and Teacher Education, 24, 1502-1515.

Swafford, J. (1998). Teachers supporting teachers through peer coaching. Support for Learning, 13(2), 54-58.

Thao, D., \& Boyd, W. (2014). Renovating early childhood education pedagogy: A case study in Vietnam. International Journal of Early Years in Education, 22(2), 184-196.

Walker, A., \& Hallinger, P. (2015). A synthesis of reviews of research on principal leadership in East Asia. Journal of Educational Administration, 53(4), 554-570. 